\title{
Elektrotherapie in Violett
}

\section{Iris Ritzmann}

Prof. Dr. med. et lic. phil, Universität Zürich, Mitglied der Redaktion Medizingeschichte

Wer mit alten medizinischen Geräten zu tun hat, kennt vermutlich die Anfrage. Auf dem Dachboden sei ein alter Koffer zum Vorschein gekommen, und darin befinde sich ein elektrischer Apparat mit zahlreichen gläsernen Aufsätzen in verschiedensten Formen. Der Bezug mit imitiertem Krokodilleder und die oft aufwendige samtene Innenauskleidung bestärken die Überzeugung, es müsse ein besonders seltenes Objekt sein.

Um es gleich vorwegzunehmen: Es handelt sich um einen Hochfrequenzapparat, der vor allem in den 1920er Jahren in riesigen Mengen und weit über 100 Typen auf den Markt kam. Doch gerade als Alltagsgegenstand sind ihm Geschichten eingeschrieben, die von längst vergessenen, einst modernen medizinischen Vorstellungen und Praktiken berichten. Der Einzug der Elektrizität in weite Lebensbereiche verhalf der Elektrotherapie zu hohem Ansehen. Hochfrequenzapparate standen nicht nur in Arztpraxen und Friseursalons, sondern als luxuriöse Geräte in vielen Privathaushalten.

Mit der Stärkung der Lebenskraft versprachen sie Linde-

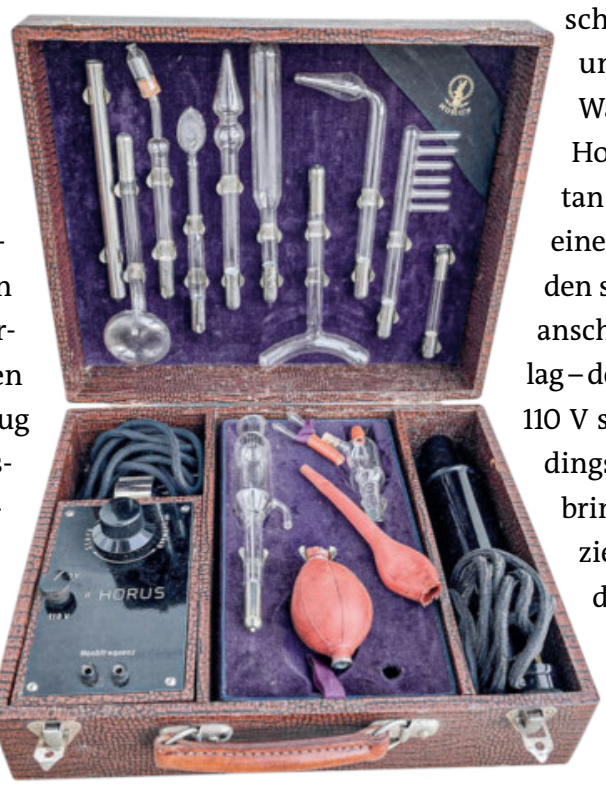
Hochfrequenzapparat der Firma Horus, 1920er Jahre, Privatbesitz Dr. I. Pugatsch. rung gegen ein weites Panorama unterschiedlicher Leiden, was die Formenvielfalt der mit Edelgas gefüllten Glaselektroden verrät. So liessen sich mit der Kammelektrode Haarausfall, mit der Augenelektrode Augenerkrankungen, mit flächigeren Elektroden Leberleiden und Schuppenflechte bekämpfen, während sondenförmige Elektroden in Nasen, Rachen oder Ohren ihre Heilwirkung entfalteten. Zum Set gehören auch Vagina- und Mastdarm-Elektroden, die mittels Erregung nervöse Leiden wie die Hysterie oder Neurasthenie zu lindern versprachen - oder anderen Reizen dienten.

Der hier dargestellte Hochfrequenzapparat wurde von der Firma Horus in Leipzig hergestellt. Laut seinem jetzigen Besitzer stammt er von einem Untermieter, der knapp bei Kasse war und seiner Vermieterin in den 1920er Jahren das Gerät an Geldes statt überliess. Dieses satz mit Gummiteil im unteren Kofferbehältnis auf. Es handelt sich um eine "Ozoninhalator-Elektrode», die bei Halskrankheiten, Bronchialkatarrh, Asthma und anderen Lungenleiden zum Einsatz kam. In die mittlere Glasöffnung wurden ätherische Öle eingefüllt. Der Luftstrom, der mit dem Gummiball in den Glaskolben gepumpt wurde, zerstäubte das Öl, während die Hochfrequenzstrahlung den Luftsauerstoff in hochwertiges Ozon verwandelte. Nun wurde das antiseptische Ozongemisch zur Nase geführt und inhaliert.

Warnung: Bitte verbinden Sie einen Hochfrequenzapparat niemals spontan mit dem Stromnetz! Ich habe schon einen neugierigen Kollegen betreut, der den seltsamen Apparat testen wollte und anschliessend mit Herzrasen am Boden lag-der historische Transformator war auf $10 \mathrm{~V}$ statt auf $220 \mathrm{~V}$ eingestellt. Wer allerdings ein solches Gerät zum Laufen bringt, erlebt sein violettes Wunder: Die zierlichen Glasaufsätze beginnen durch die Ionisierung des Edelgases wundersam farbig zu leuchten und sprühen winzige Blitze, wenn sie sich der Haut nähern. Die von Fachärztinnen und Fachärzten attestierte Wirksamkeit dieser Therapie lässt vielleicht Zweifel an der Glaubwürdigkeit medizinischer Expertise aufkommen, sie führt zugleich die Komplexität erfolgreicher Behandlungen vor Augen: Hochfrequenzapparate feiern zurzeit ein triumphales Comeback.

\section{Bildnachweis}

Iris Ritzmann, 2021

\section{Weiterführende Literatur}

1 Löffelbein N. Nerven unter Strom - Sinnüberschuss und Sinnreduktion von "Neurasthenie-Objekten» in Deutschland (18801930). In: Virus - Beiträge zur Sozialgeschichte der Medizin. 2020;19:181-207.

2 Moll FH, et al. Die Urologie wird elektrisch - Elektrotherapie. Der Urologe. 2020;59:326-40. https://doi.org/10.1007/s00120-02001122-y

3 Müller S. Ein Zauberstab verspricht Heilung. Wie der Hochfrequenz-Apparat in den Zwischenkriegsjahren als Allheilmittel inszeniert wurde. Seminararbeit Luzern 2020. https://doi. org/10.5281/zenodo.4018888

4 Neumann, Sebus. Hochfrequenz für Kranke und Gesunde. Ein ärztlicher Ratgeber. Jena 1925. http://www.electrotherapymuseum.com/2005/HF/ 